\title{
MODELING AND CONTROL OF A SMALL WIND TURBINE
}

\author{
Md. Arifujjaman \\ M. Engg. Student \\ Memorial University of \\ Newfoundland \\ email: \\ arifujjaman@engr.mun.ca
}

\author{
M. Tariq Iqbal \\ Assistant Professor \\ Memorial University of \\ Newfoundland \\ email: \\ tariq@engr.mun.ca
}

\author{
John E. Quaicoe \\ Professor \\ Memorial University of \\ Newfoundland \\ email: \\ jquaicoe@engr.mun.ca
}

\author{
M. Jahangir Khan \\ Ph. D Student \\ Memorial University of \\ Newfoundland \\ email: \\ mjakhan@engr.mun.ca
}

\begin{abstract}
This paper starts with a detailed survey of control methods commonly employed by commercially available small wind turbines. This detailed survey indicates that the most commonly used control method of small wind turbines is horizontal furling method. Such furling mechanism and resulting dynamics are described in the paper. Furling is used to control the aerodynamic power extraction from the wind. A dynamic model of a small wind turbine with furling dynamics is presented in this paper. Such small wind turbines are based on permanent magnet generators and their speed can be regulated using the load control. The extraction of maximum power output from such wind turbines is investigated using tip speed ratio control and hill-climbing control methods. The system is simulated in Matlab/Simulink to determine a suitable control strategy.

Two dynamic controllers are designed and simulated. In the first method, a controller uses the wind speed and rotor speed information and controls the load in order to operate the wind turbine at the optimum tip speed ratio. The generator output is observed in varying wind condition as the furl angle increases and decreases. In the second method, a controller compares the output power of the turbine with the previous power and based on the comparison it controls the load. Using a hill-climbing algorithm the controller tries to extract the maximum power from the wind, while the generator output is observed as the furl angle increase or decreases. Finally, the output of these two controllers is compared and investigated to determine which controller leads to the best results.
\end{abstract}

Keywords: Furling control, wind turbine, wind energy, Hillclimbing,

\section{Introduction}

Wind technologies have been developing rapidly over the last few decades, as it is renewable, cost-effective and also cause little harm to the nature with respect to other conventional energy. One of the most important tasks of a control strategy for wind turbines is to limit the power input to the turbine to a level that the mechanical and electrical components of the turbine are able to handle. This must be achieved by reducing the power extracted from the wind. Large wind turbines are complex in operation, deploy multitude of control methods and operate in grid-connected mode. On the other hand, small wind turbines can be used for stand-alone as well as grid-connected system. An extensive review has been done to survey the control methods that are most commonly used by the manufacturers in their commercially available small wind turbines. Furling (horizontal/vertical), flapping, passive pitching and soft stall are the most common control methods that are being used now-a-days in most commercial available small wind turbines in the market for their over speed and power control capacity. This survey has also indicated that most of small wind turbines use horizontal furling method for mechanical power control. In this method the rotor furls or turns away from the direction of the wind as the wind speed increases. This causes effective wind speed to decrease on the rotor plane and thus aerodynamic power of the wind turbine is lowered. This turn away action is normally termed as furling action. Furling control is very effective and cheap method of control of small wind turbines. Whereas, soft stall method is the probably the simplest and cheapest method and it is also easy to implement. [1]. With such system, it is possible to meet the load demand of a small house. Also the system can be tied with the grid. This paper discusses two suitable control strategies to extract the maximum power from a small wind turbine. Firstly, a suitable controller has been designed to control the load connected to the system to maintain an optimum tip speed ratio of the wind turbine (Tip Speed Ratio control). The optimum tip speed ratio will ensure that the wind turbine is extracting the maximum power from the variable wind speed conditions. The controller will adjust the load connected to the system. In the second strategy, the controller will try to adjust the load by measuring the consecutive power and thus the extraction of maximum power from the wind (Hill-climbing control). This paper is divided into several sections. The first section is a short overview of the furling control method of small wind turbines. The second section is the modeling of a small wind turbine with furling dynamics and also the modeling of the total system. The third section contains the simulation results. Finally, some discussion and conclusion are highlighted.

\section{Modeling of System Components}

A stand-alone variable speed wind turbine when connected to a load should be controlled to extract the maximum power. Several works has been done to extract the maximum power out of the turbine [2-5]. Dynamic modeling and simulation is required to determine the suitable controller of the wind 
turbine connected to a load. The wind turbine and the associated components have modeled by the following equations.

The output power of the wind turbine can be expressed as,

$$
\mathrm{P}_{\mathrm{aero}}=0.5 \rho \mathrm{A} \mathrm{Cp}(\lambda) \mathrm{V}^{3}
$$

The torque produced by the wind turbine is then:

$$
\mathrm{T}_{\mathrm{w}}=\mathrm{P}_{\mathrm{aero}} / \omega_{\mathrm{m}}
$$

Where, $\omega_{\mathrm{m}}=$ Angular velocity of the wind turbine rotor ( $\mathrm{rad} / \mathrm{s})$. Also, the tip speed ratio $\lambda$ is given in terms of rotor speed, $\omega_{\mathrm{m}}$ and wind speed, $\mathrm{V}(\mathrm{m} / \mathrm{s})$ as:

$$
\lambda=\mathrm{R} * \omega_{\mathrm{m}} / \mathrm{V}
$$

Where $\mathrm{R}$ = the radius of the wind turbine rotor $(\mathrm{m})$.

Therefore, the torque term becomes

$$
\mathrm{T}_{\mathrm{w}}=0.5 \rho \mathrm{ACp}(\lambda) \mathrm{V}^{3} / \omega_{\mathrm{m}}=0.5 \rho \mathrm{AR} \mathrm{Cp}(\lambda) / \lambda * \mathrm{~V}^{2}
$$

But, we know, Torque co-efficient $=$ Ct $(\lambda)=\operatorname{Cp}(\lambda) / \lambda$. When the wind speed increases it produces an angle $\theta$ with the horizontal axis. The effective wind velocity at the rotor plane will be $V \cos \theta$ [6]. Putting all these values, we get the final expression of the torque as:

$$
\mathrm{T}_{\mathrm{w}}=0.5 \rho \mathrm{AR} \mathrm{Ct}(\lambda)^{*}(\mathrm{~V} \cos \theta)^{2}
$$

The wind turbine is considered to be of similar to Bergey Excel - $\mathrm{S}$ rating and incorporates furling mechanism and is based on permanent magnet synchronous generator (PMSG). The permanent magnet synchronous generator has been modeled in the rotor reference frame. If we assume zero sequence quantities are not present and apply Park's transformation, the terminal voltage of the PMSG in the rotor reference frame can be expressed as [7]:

$$
\begin{aligned}
& V^{g}{ }_{q}=-\left(R^{g}+p L^{g}\right) i^{g}{ }_{q}-\omega_{r} L^{g}{ }_{q} i^{g}+\omega \lambda_{m} \\
& V^{g}{ }_{d}=-\left(R^{g}+p L^{g}\right) i^{g}{ }_{d}+\omega_{r} L^{g}{ }_{q} i^{g}{ }_{q}
\end{aligned}
$$

Where $\mathrm{R}^{\mathrm{g}}=$ stator phase winding resistance $(\Omega)$.

$\mathrm{L}_{\mathrm{q}}^{\mathrm{g}}=$ stator inductance in the quadrature axis $(\mathrm{H})$.

$\omega_{\mathrm{r}}=$ rotor angular velocity of the generator $(\mathrm{rad} / \mathrm{s})$

$\lambda_{\mathrm{m}}=$ Flux linkage $(\mathrm{V}-\mathrm{s} / \mathrm{rad})$

$\mathrm{p}=$ operator $\mathrm{d} / \mathrm{dt}$

The electromagnetic torque in the rotor reference frame may be written as

$$
\mathrm{T}_{\mathrm{e}}=(3 / 2)(\mathrm{P} / 2)\left[\left(\mathrm{L}_{\mathrm{d}}^{\mathrm{g}}-\mathrm{L}_{\mathrm{q}}^{\mathrm{g}}\right) \mathrm{i}_{\mathrm{q}}^{\mathrm{g}} \mathrm{i}_{\mathrm{d}}^{\mathrm{g}}-\lambda_{\mathrm{m}}\right) \mathrm{i}_{\mathrm{q}}^{\mathrm{g}}
$$

Where $\mathrm{P}=$ Number of poles of the PMSG.
The relation between the angular velocity of the generator $\omega_{\mathrm{r}}$ and mechanical angular velocity of the rotor $\omega_{\mathrm{m}}$ can be expressed by:

$$
\omega_{\mathrm{r}}=(\mathrm{P} / 2) \omega_{\mathrm{m}}
$$

The rotational speed and the torque produced by the wind turbine can be related as:

$$
\mathrm{T}_{\mathrm{w}}=\mathrm{J}(2 / \mathrm{P}) \mathrm{p} \omega_{\mathrm{m}}-\mathrm{T}_{\mathrm{e}}+\mathrm{B} \omega_{\mathrm{m}}
$$

A small friction term has been added in the generator for making it more realistic. $\mathrm{T}_{\mathrm{w}}$ is the torque produced by the wind turbine and should be the input to the PM.

The stator voltage of the PM can be expressed as

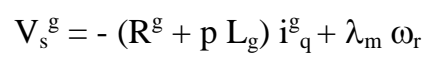

As we did not consider the rectifier as a controlled one, so the delay angle $\alpha$ of the rectifier will be zero. As a result the direct axis current $\mathrm{i}_{\mathrm{d}}^{\mathrm{g}}=0$ [7].

In terms of rotor reference frame quantities and the assumption of non-existence of zero sequence current, we can write:

$$
V_{R} I_{R}=(3 / 2)\left(V^{g}{ }_{q} i_{q}^{g}+V^{g}{ }_{d} i^{g}{ }_{d}\right)
$$

Since $\mathrm{V}_{\mathrm{d}}^{\mathrm{g}}$ is zero and same as $\mathrm{i}_{\mathrm{d}}^{\mathrm{g}}$, we can write:

$$
\mathrm{i}_{\mathrm{q}}^{\mathrm{g}}=\left(\mathrm{V}_{\mathrm{R}} \mathrm{I}_{\mathrm{R}}\right) /\left(3 / 2 * \mathrm{~V}_{\mathrm{q}}^{\mathrm{g}}\right)
$$

The simplified dc output voltage of the rectifier can be expressed as

$$
\mathrm{V}_{\mathrm{R}}=(3 * \sqrt{3}) \mathrm{V}_{\mathrm{s}}^{\mathrm{g}}
$$

And the current will be:

$$
\mathrm{I}_{\mathrm{R}}=\mathrm{P}_{\text {load }} / \mathrm{V}_{\mathrm{s}}^{\mathrm{g}}
$$

The power inverter has been modeled by the basic principle of pulse width modulation (PWM) operation. Then a simple series RL load model has been considered as a load.

The wind turbine has been considered as a direct drive system. The generator is connected to the load through a rectifier and an inverter. The controller controls the value of load to maintain a desired output. In the first system, tip speed ratio control is employed assuming an optimum tip speed ratio of 7.5(Figure 1). In this control strategy operation of the wind turbine at an optimal tip speed ratio will ensure that maximum energy is extracted from wind. In the second strategy, the load has been controlled using the hill-climbing algorithm based on 
the measurement of power (Figure 2). In the first strategy, operation the wind turbine at an optimal tip speed will ensure that the wind turbine will extract the maximum energy while in the hill-climbing algorithm will ensure that the maximum power is extracted from the wind. It should be noted that in the second strategy it does not require a wind speed measurement.

\section{Simulation results}

The system that has been described before was simulated using Matlab-Simulink ${ }^{\mathrm{TM}}$ blocks. The load that has been considered here is a simple RL load, which is mainly used for home appliances.

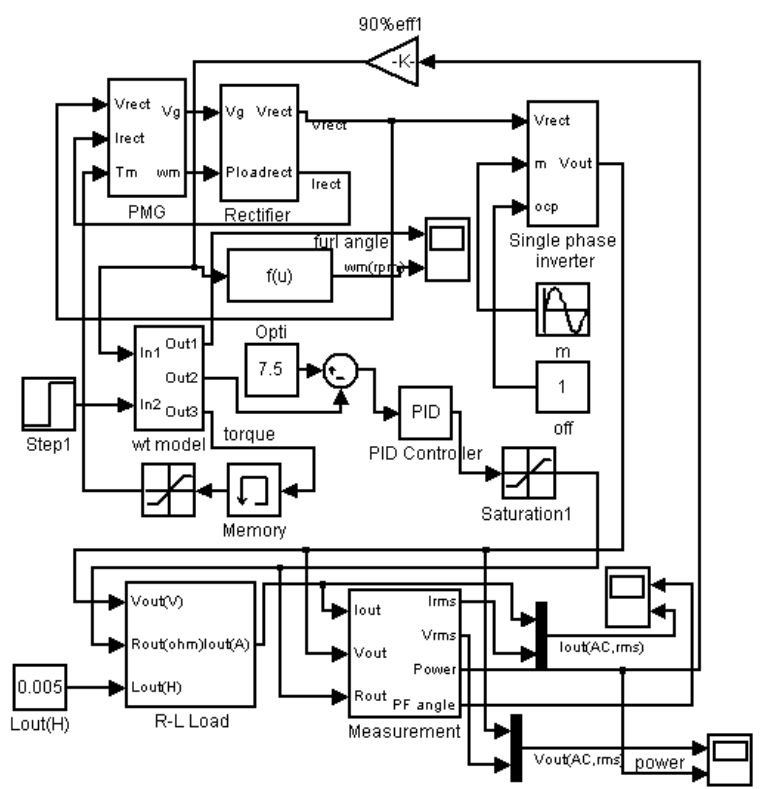

Figure 1: Optimum tip speed ratio control of wind turbine

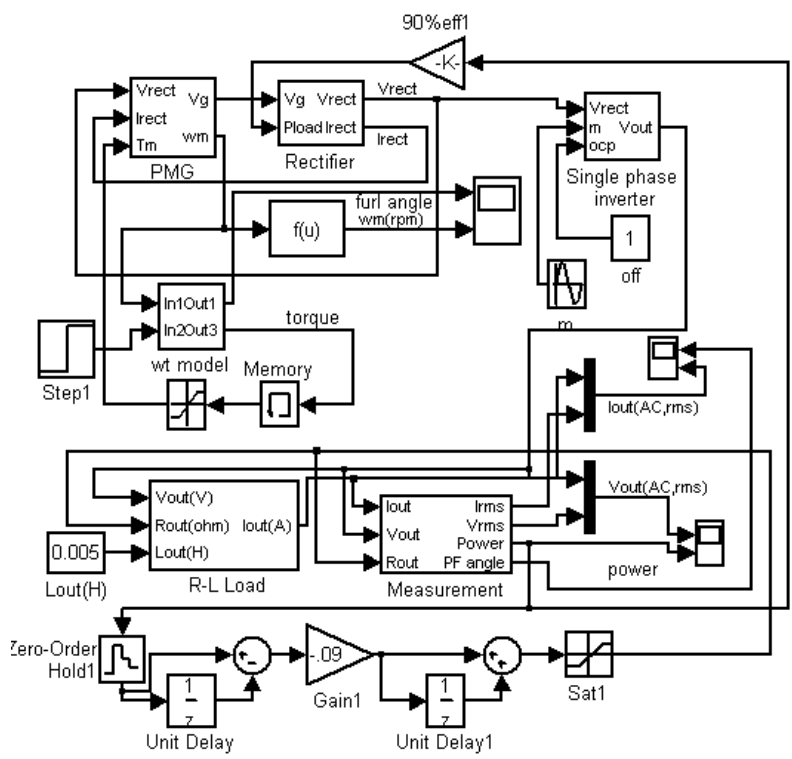

Figure 2: Hill-climbing control of wind turbine

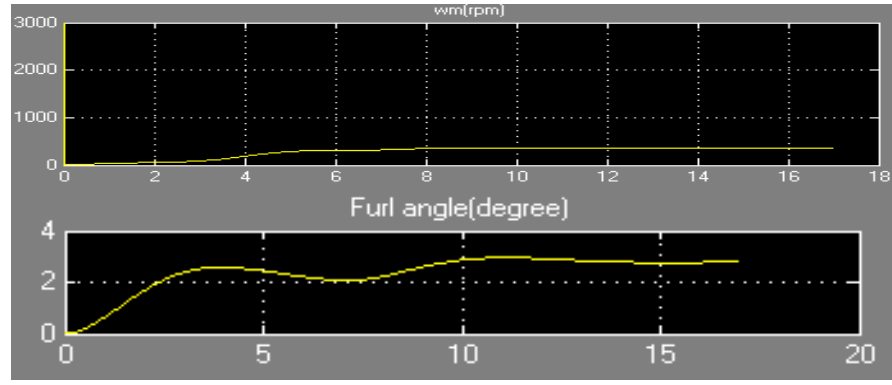

Figure 3: Step response of the turbine with a PID controller. (Wind speed increase from $11.5 \mathrm{~m} / \mathrm{s}$ to $12.5 \mathrm{~m} / \mathrm{s}$ at 7 second)

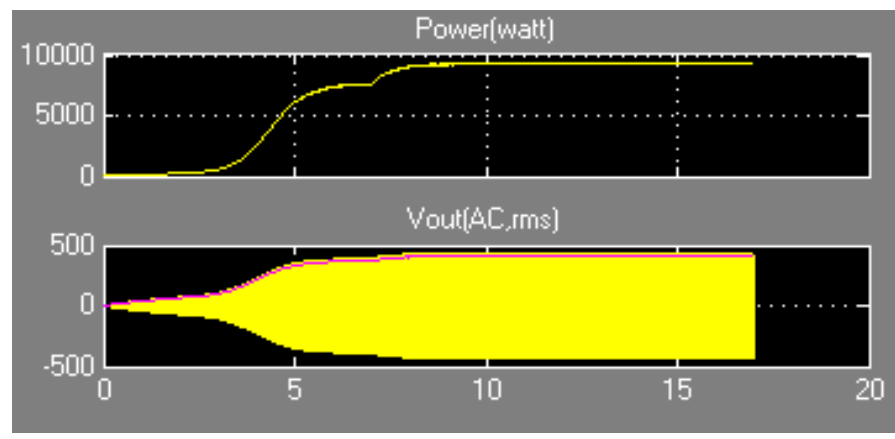

Figure 4: PWM output of the inverter during tip speed ratio control

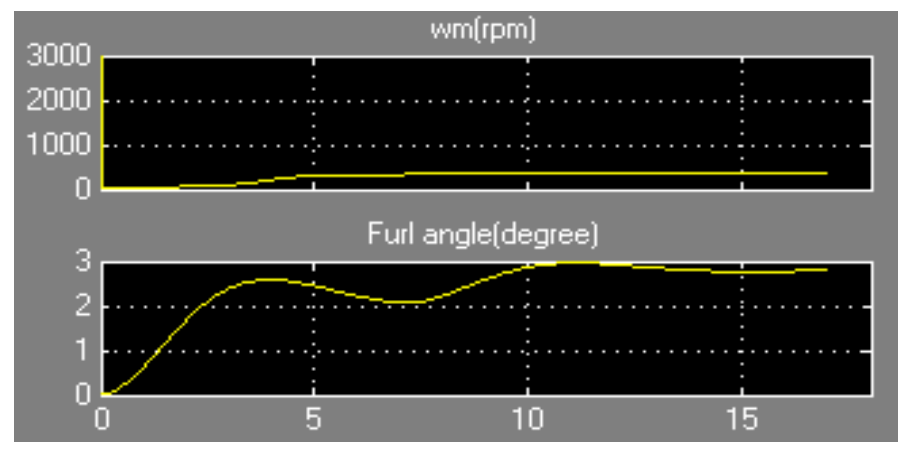

Figure 5: Step response of the turbine with hill-climbing controller. (Wind speed increase from $11.5 \mathrm{~m} / \mathrm{s}$ to $12.5 \mathrm{~m} / \mathrm{s}$ at 7 second)

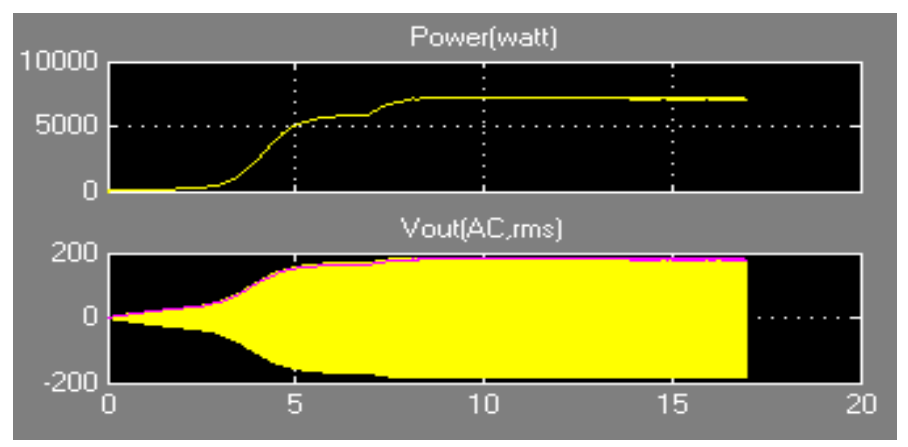

Figure 6: PWM output of the inverter during hill-climbing control.

The output of the rectifier has been converted into AC by a simple inverter and the load has been adjusted using the controller parameters. At the first strategy a PID controller has adjusted the load. The controller value has been calculated 
simple Ziegler-Nichols (ZN) method. The suitable controller parameter has been found as; $\mathrm{Kp}=2.31 ; \mathrm{Ki}=49.5, \mathrm{Kd}=0.01675$. Figure 1 showing the simulation model using for tip speed ratio control strategy. Figures 3 and 4 shows the result of the simulation. A step input of $11.5 \mathrm{~m} / \mathrm{s}$ to $12.5 \mathrm{~m} / \mathrm{s}$ has been applied after a stable condition (7 sec). The simulation has started from 7 second and within 17 second all the quantities has reached to a steady state value. The furling angle and generator speed (RPM) is increasing with the increase in wind speed and has come in a stable state within 10 second (Figure 3). Figure 4 shows output voltage of PWM inverter.

In the tip speed ratio control method, it needs the information about the instantaneous wind speed. But it is quite tough to measure the wind speed accurately because wind turbine experiences a different force on their rotor. From this point of view hill climbing algorithm can work efficiently against the tip speed ratio control method. Compared to tip speed ratio control, hill-climbing method is based on the measurement of power. Two consecutive power measurements are used to determine the change in the power. The load is adjusted using the difference of the power. Figure 2 shows the simulation model of the hill-climbing algorithm. The load has adjusted every one-tenth of a second to extract maximum power. Suitable gain has found to be -0.009 . Figure 5 and 6 shows the simulation results. A step input of $11.5 \mathrm{~m} / \mathrm{s}$ to 12.5 $\mathrm{m} / \mathrm{s}$ has been applied after 7 seconds. The furling angle in gradually increasing and the same is with rotor speed. Within 10 seconds they have came again in a stable state condition (Figure 5). In Figure 6, the load voltage is gradually increasing and after a short time it has reached in a stable value. The same conclusion can be drawn for the power. The hill- climbing algorithm also behaves like a bang-bang controller in an effort to extract power from the wind turbine.

Various challenges of system simulation have been experienced during simulating the models. Limiters and memory elements have been placed in several nodes to eliminate convergence problems. However, this limits the range of effective parameter variations. In particular, the hillclimbing algorithm faced great convergence problems. In further works, methods of removing such limitations will be reported.

\section{Conclusions}

The paper has discussed dynamic modeling and control of small wind turbine with furling dynamics. The wind turbine has been modeled based on a permanent magnet synchronous generator and uses controllers employing tip speed ratio control and hill climbing algorithm. A PID controller has been used to control the load. A proportional controller was sued for the hill-climbing method. Previous research has converged that with the use of power system block the simulation time is large enough but in this paper with the implementation of Simulink block it has been seen that the computation time has greatly reduced. Further effort can be focused on comparison of energy capture of these two strategies.

\section{Acknowledgements}

Authors would like to thank National Science and Engineering Research Council (NSERC) for providing support for this research.

\section{References}

[1] Muljadi,E., Forsyuth, T,. Butterfield, C.P., "Soft-stall control versus furling control for small wind turbine power regulation," Proceedings of Wind Power 1998, Bakersville, CA.

[2] Datta, R.; Ranganathan, V.T.; "A method of tracking the peak power points for a variable speed wind energy conversion system" IEEE Transactions on Energy Conversion, Vol: 18, Issue: 1, March 2003.

[3] Iqbal, M.T., Coonick, A., "Dynamic control of a stand alone wind turbine,” BWEA-16 annual conference, 1994.

[4] Mohamed, A. Z., Eskander, M.N., and Ghali, F.A., "Fuzzy logic control based maximum power tracking of a wind energy system," Renewable energy, Vol. 23, No 2, 2001.

[5] Wang, Q.; Chan, L.; “An independent maximum power extraction strategy for wind energy conversion systems" IEEE Canadian Conference on Electrical and Computer Engineering, Vol.: 2, 1999.

Bialasiewicz, J.T. "Furling control for small wind turbine power regulation”, ISIE '03, Vol.: 2, 2003.

[7] Borowy B.S.; Salameh, Z.M.; "Dynamic response of a stand-alone wind energy conversion system with battery energy storage to a wind gust”, IEEE Transactions on Energy Conversion, Vol.: 12, Issue: 1, March 1997.

\section{Appendix}

Wind Turbine: BWC Excel - S
$\begin{aligned} & \text { Rating: } \\ & \text { Rotor radius: }\end{aligned} \quad \mathrm{R}=3.2004 \mathrm{~m}$ (21 feet)
$\begin{array}{ll}\text { Furling wind speed: } & 15.6 \mathrm{~m} / \mathrm{s}(35 \mathrm{mph}) \\ \text { Generator: Permanent Magnet Alternator: } & \\ \text { Phase Resistance } & \mathrm{R}^{\mathrm{g}}=0.5 \Omega \\ \text { Phase Inductance } & \mathrm{L}^{\mathrm{g}}=4.48 * 10^{-3} \mathrm{H} . \\ \text { Flux Linkage } & \lambda_{\mathrm{m}}=0.39 \mathrm{~V}-\mathrm{s} / \mathrm{rad} \\ \text { Number of Poles } & \mathrm{P}=38 \\ \text { Inertia } & \mathrm{J}=25 \mathrm{kgm}^{2} \\ \text { Damping Coefficient } & \mathrm{B}=0.00035 \mathrm{Nm}-\mathrm{rad} / \mathrm{s}\end{array}$

